\title{
Export Planning and Performance: An Organizational Culture Perspective on Small Firms
}

\author{
Philip D. OIson \\ Newell Gough
}

The purpose of this study is to examine hypothesized relationships among small firms' cultural values pertaining to formal planning, their practices linked to those values, and their export performance. Sample results indicate that significant relationships exist between export planning values and practices, and between the planning practice of using advisors and export performance.

$\mathbf{E}$ xporting is a frequently discussed topic today within both public and private sectors. In the public sector, people tend to focus on exporting from an economic development and job creation point of view. In the private sector, leaders of firms often discuss it as a growth strategy. It is common knowledge that large firms are frequent exporters. Less well known, however, is the fact that small (and new) firms increasingly ship their products abroad. The focus of this study is on small business exporting.

Research on small business exporting has grown in recent years (e.g., Aaby and Slater, 1989; Bijmolt and Zwart, 1994; Caruana, Morris and Vella, 1998; Kamath, Rosson, Patton, and Brooks, 1987; Lee and Jang, 1998; Miesenbock, 1988; Zahra, Neubaum and Huse, 1997). Although past research has improved our understanding of export concepts and relationships, information gaps still exist. For example, little information is available about the export planning-performance relationship. Studies in this area are scarce, at least those with an export start-up focus, because early export research found that unsolicited export orders were what triggered many firms to start exporting (Bilkey, 1978; Brasch and Lee, 1978). Consequently, in past years many firms used a reactive export strategy. However, these practices are changing. In newer industries, for example, where exporting is more common and in some cases expected, firms are more frequently preplanning or soliciting export sales (a proactive export strategy).

This strategic change raises a number of importantand unresolved-export planning and performance issues. To address these concerns, information is needed on a number of variables, one of which is planning practices. A research question in this area is: Which export planning "practices" improve organizational performance? Other factors that could be examined are the values, beliefs, and norms held by organizational members toward planning and performance. Relevant questions here are: Is com- prehensive planning "valued" by organizational leaders? Do organizational members share the "belief" that better performance usually results from explicit rather than nonexplicit planning? What planning "norms" are organizational members expected to follow? These questions, taken together, cover key elements of an organization's culture. In recent years, organizational culture has received considerable attention in the literature. Numerous studies (e.g., Deal and Kennedy, 1982; Denison, 1990; Ouchi, 1981; Peters and Waterman, 1982; Schein, 1985; Trice and Beyer, 1993) have been published on the subject.

The purpose of this study is to use an organizational culture perspective to empirically examine the planningperformance relationship at the export start-up stage in small businesses. It is believed that this perspective can shed additional light on our understanding of successful export practices. Background information on the planningperformance relationship and culture topics along with a model and hypotheses are presented next, followed by sections covering methodology, results, and discussion.

\section{Literature Review}

This section examines past studies on strategic management and organizational culture. It also proposes a model of strategic planning culture and its relationship to organizational outcomes.

\section{Strategic Management}

Most strategic management studies on the planning-performance relationship have focused on large firms and their domestic rather than international operations. Central to this research has been the effect of planning methods on firm performance, with a significant issue being the impact of "formal" planning on firms' performance (Shrader, Taylor, and Dalton, 1984). Formal is defined in different ways by researchers. Armstrong (1982) mentions the use of an explicit goal achievement process, while Fredrickson (1984) emphasizes the use of a comprehensive planning process.

In addition to differences in the definition of formal planning, there are also differences concerning how to operationalize this concept. One way to gauge the formality of planning is to measure the degree to which the planning process generates written documentation. This approach 
was employed first by large business researchers and most small business researchers have continued using written documentation (the completeness of a business plan) to measure formal planning (Bracker, Keats, and Pearson, 1988; Gilmore, 1971; Robinson and Pearce, 1983; Rue and Ibrahim, 1998; Still, 1974). In these instances, planning is usually measured either as a dichotomy referring to the absence or presence of a written plan; or a continuum where planning comprehensive levels such as no written plan, partial written plan, and complete written plan are included (Pearce, Freeman, and Robinson, 1987). Some researchers, however, question whether this large firm prescription is relevant to small firms (Robinson, 1982).

In this vein, data exist which suggest that written business plans are not used as extensively by successful small businesses as business experts might believe (Parks, Olson, and Bokor, 1991; Schuman, Shaw, and Sussman, 1985). For example, Parks et al. (1991) found in a survey of 120 INC. 500 firms that only 17.5 percent had a complete written plan, 32.5 percent had a partial plan, and 50 percent had no written plan at start-up. Furthermore, when the research from both large and small businesses on the impact of preparing written plans on performance is considered, the findings are mixed. That is, some studies have shown positive results (Fredrickson, 1984; Lyles, Baird, Orris, and Kuratko, 1993) while others have not been able to demonstrate this relationship (Bresser and Bishop, 1983; Hand, Sineath, and Howle, 1987).

Another way to operationalize the formality of planning is to measure the degree to which external and/or internal counsel is relied upon in the strategic planning process. Robinson (1982) has proposed that "outsider" involvement in planning indicates a serious commitment to a formal strategic planning orientation in small firms. Outsider involvement refers to both boards of directors and management consultants-people who would appear to be able to supplement a small firm leader's lack of skills in, and time for, formal planning. Limited empirical research exists on the impact of the use of advisors on performance. The results from one study in this area (Robinson, 1982) were that profitability and improvement in effectiveness were higher for small firms which engaged in outsiderbased strategic planning than for firms which did not.

Overall, past researchers have found the impact of formal planning on performance unclear. Differences in definitions as well as ways of operationalizing formal planning have contributed to these findings. Moreover, Pearce, Freeman, and Robinson (1987) have argued that authors of past studies have not considered or controlled for other relevant variables (both inside and outside an organization) that can influence the planning-performance relationship. Inside variables include leadership style and other behavioral patterns (i.e., organizational culture) as well as organi- zational structure/design. Outside forces include industry life-cycle stage and competition. Given this concern, it would be helpful to examine the planning-performance relationship from an organizational culture perspective.

\section{Organizational Culture}

Trice and Beyer (1993) define organizational cultures as collective phenomena that include two components:

1. substance, an organization's ideologies or the systems of beliefs, values and norms that are shared by its members, and

2. forms, the observable ways members of an organization express the organization's ideologies (i.e., the practices and behaviors of an organization's members).

Trice and Beyer (1993) state further that the ideologies, or substance of cultures, are shared interrelated sets of emotionally charged beliefs, values, and norms that hold people in an organization together and help them cope with work uncertainties and ambiguities. These authors also define beliefs as expressed cause and effect relations (i.e., statements about which behaviors will lead to which outcomes), values as expressed desires or preferences for certain behaviors or outcomes, and norms as expressed behaviors that are expected by organizational members. While cultural substance issues (ideologies) are abstractions, cultural forms are concrete, observable entities through which members of a culture communicate substance to one another. Four categories of cultural forms are: symbols, language, narratives, and practices.

Applying the organizational culture.perspective to the planning-performance relationship suggests that past planning-performance studies have fockused on forms of planning cultures, not substance. That is, past research has concentrated on practices-use of written plan and advisors-and not on planning beliefs, values, and norms. This recognition may be important because small business founders/leaders will likely differ on their planning ideologies. For example, some leaders will value formal planning, others will not. One distinguishing feature of using an organizational culture perspective is that both the substance and forms of planning culture are explored.

\section{Model and Hypotheses}

The proposed model of strategic planning culture and its relationship to organizational outcomes is contained in Exhibit 1. The model was developed based on Denison (1990, see, in particular, pp. 1-6), and Trice and Beyer (1993). Of interest in the current study is its application to export planning.

The model recognizes that a planning culture has two related components or levels: 


\title{
Exhibit 1 \\ Planning Culture Model
}

\begin{abstract}
Planning Substance (Beliefs, Values, Norms)
Leaders believe formal planning improves performance

*Leaders value formal planning

Leaders expect organizational members to be formal planners
\end{abstract}

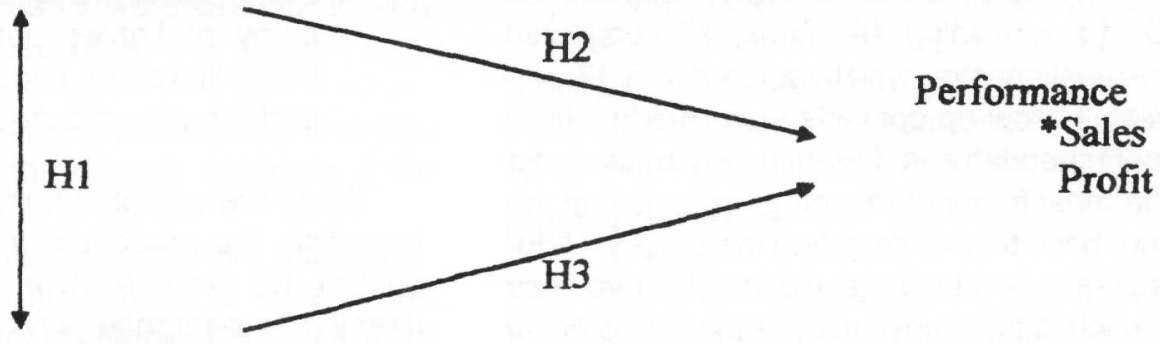

\section{Planning Forms (Practices, Behaviors)}

*Prepare written plans

*Use planning advisors

Contact customers frequently

Note: Only some of the different possible planning beliefs, values, norms, practices, behaviors, and performance outcomes are listed. Starred items are tested in the current study.

1. substance or an organization's ideologies about planning beliefs, values, and norms; and

2. forms or observable planning practices and behaviors that are used to express these planning ideologies.

The model also proposes that relationships exist between each of these planning culture components and performance. Only a few of the different possible planning beliefs, values, norms, practices, behaviors and performance outcomes are listed in Exhibit 1. In the current study the starred items are tested.

The hypotheses for the study involve the founders/leaders of small businesses. Trice and Beyer (1993) state that a firm's cultural ideologies and forms can be influenced by its founders and managers. In particular, leaders of new and small firms have considerable control in creating the cultures of their organizations. The first two hypotheses ( $\mathrm{H} 1 \mathrm{a}$ and $\mathrm{H} 1 \mathrm{~b})$ concern relationships between export planning substance and forms.

Hypothesis 1: Small businesses whose leaders support (value) formal export planning correspond with small businesses that employ the following practices: prepare written export plans (H1a), and use export planning advisors (H1b).

The next hypothesis focuses on the relationship between the substance of export planning cultures and export performance.

Hypothesis 2: Small businesses whose leaders support (value) formal export planning outperform those whose leaders who do not support this activity.

The final two hypotheses ( $\mathrm{H} 3 \mathrm{a}$ and $\left.{ }^{\mathrm{H}} \mathrm{H} 3 \mathrm{~b}\right)$ cover relationships between the forms of export planning cultures and export performance.

Hypothesis 3: Small businesses which employ the following export planning practices outperform those which do not: prepare written export plans (H3a), and use export planning advisors (H3b).

\section{Methodology}

This section examines the methodology employed in the study.

\section{Sample}

To examine this study's hypotheses, a sample of firms that export products from the state of Idaho was obtained. Each firm was sent a questionnaire designed and pretested by the current authors. The mail survey followed Dillman's (1978) total design methodology. This method consists of 
an initial mailing, a postcard reminder in one week, and a second mailing two weeks after the post card reminder. Each mailing includes a questionnaire in booklet format and a self-addressed stamped envelope.

The sample was obtained from a list of 473 Idaho firms contained in the Idaho International Trade Directory 199495. This list included the name of a contact person to whom the questionnaire was mailed. Positions held by the contact person included CEO, owner, president, and marketing manager. Twenty-one questionnaires were returned as undeliverable. Of the remaining 452 firms, 78 completed and returned the questionnaire, which resulted in a 17 percent response rate. Follow-up contacts were made with 2 percent of the nonrespondents to determine the reasons for nonresponse. The most frequent reason given was that the firm leaders did not have time to complete the survey. Other reasons were that the respondents did not believe they could contribute much to the study because exporting was a negligible part of their businesses, and that the people who knew the requested information were no longer with the firm.

The information needed from the surveyed firms dealt with their export start-up stage and their first year of exporting. This year was some year prior to 1995 for all the sampled firms. (The directory included all Idaho exporters regardless of their date of export initiation and the initial sample contained 78 of these firms.) Because the focus of this study is small firms, and because remembering facts about a firm's early export years becomes more difficult the longer a firm exports, those firms with 100 or more employees at export initiation and those whose first export predated 1985 were eliminated from the analysis. In this process, 28 firms were excluded, reducing the sample to 50 firms. The average number of employees for these 50 firms during their first year of exporting was 20 and the standard deviation was 23 . On average, the 50 firms started exporting in 1993. Additional descriptive information about the sample is presented in the results section.

\section{Measures}

Four measures were used to gather data for this study's hypotheses. Three of the four measures concerned a firm's preexport period-the year preceding receipt of the first accepted export order. These questions were:

1. Did your firm's leaders support (value) a culture toward exporting which emphasized being explicit, comprehensive, or thorough with strategic export information? The responses were: (a) yes, or (b) no.

2. When planning for exports, did your firm use: (a) no written export plans; (b) written export plans that included objectives, strategies, and resource requirements; or (c) written export plans that includ- ed objectives, strategies, and resource requirements as well as control procedures and data regarding factors outside the firm (e.g., competitors).

3. When planning for exports, did your firms use: (a) no export advisors (e.g., boards of directors, consultants, etc.); (b) advisors for support, experience and information regarding exporting; or (c) advisors to actively shape strategic export decisions.

4. State your firm's export intensity (export sales divided by total sales) at the end of the first export year. In the literature, export intensity is the most popular performance measure.

Since the sampled firms were not in their first year of exporting, the responses were retrospective in nature. To control for retrospective biases, questionnaires were directed to personnel who were either a member of the firm's leadership when it first began exporting or had knowledge about the firm's initial exporting efforts.

\section{Results}

This section reports on the results of the export planning and performance survey.

\section{Descriptive Sample Information}

For the 50 firms in the sample, export intensity, the dependent variable, had the following characteristics:

- range of 1 to 100 percent;

- mean of 17.9 percent;

- median of 6.5 percent, and

- standard deviation of 25.2 percent.

Given these statistics, the population distribution from which the sample was drawn may not be normally distributed. Further, given that the sample had to be split into subclasses to test the study's hypotheses, small sample sizes became a concern. Due to these issues, nonparametric techniques were employed to test the hypotheses.

For the question concerning the preparation of a written export plan, the following responses were observed for the three categories:

1. Forty-four firms stated that they had no written plans;

2. Three firms stated that had prepared written export plans that included objectives, strategies, and resource requirements; and

3. Three firms replied that they had prepared written plans that included objectives, strategies, and resource requirements as well as control procedures and data regarding factors outside the firm. 
Because the number of responses for categories two (partial written plan) and three (complete written plan) were small, they were combined when the question was used to test hypotheses. The question about use of export advisors had the following responses:

- Thirty-two firms stated that no advisors were used;

- Seventeen firms replied that advisors were used for support, experience, and information regarding exporting; and

- One firm stated that advisors were used to actively shape strategic export decisions.

Again, similar to written plans, because only one firm listed category 3 , it was combined with category 2 for hypothesis testing.

The sample contained firms from different industries. Of the 50 firms, 8 were agricultural firms, 8 were in the building or mining fields, 1 was a chemical firm, 14 were machinery firms, and 19 were providers of other manufactured goods (e.g., computer, gifts, medical, recreation, and textiles). Because of the multiindustry sample, industry effects may exist. That is, if the relationships being examined in the study differ by industry, then it may be neces- sary to control for industry effects. A Kruskal-Wallis oneway analysis of variance test was conducted to test for industry effects using export intensity as the dependent variable. The test was not significant at less than the .10 level. This test provided support for treating the sample as one group in statistical analyses.

The sample was obtained through two mailings. Of the 50 firms being examined, 31 returned their questionnaires after the first mailing. Three weeks after the first mailing, a second set of questionnaires was sent to those not responding to the first one. This activity resulted in another 19 useable questionnaires. Again, a test (Mann-Whitney $U$ test) was conducted to test for any mailing effects with export intensity as the dependent variable. As with industry effects, no mail timing effects were found.

\section{Hypotheses}

The results for hypotheses $1 \mathrm{a}$ and $1 \mathrm{~b}$ are presented in Exhibit 2. The chi-square test (incorporating a correction for continuity) suggests that a greater proportion of small firms whose leaders value export planning formality, when compared with those whose leaders do not support this position, employ the following practices: prepare written export plans (1a), and use export advisors (1b).

\section{Exhibit 2}

Relationships Between Substances and Forms of Strategic Export Planning Culture

Hypothesis 1a: Formal export planning as a value and preparation of written export plans. ${ }^{a}$

\section{Value Formal Planning}

$\begin{array}{ll}\text { No } & \text { None } \\ \text { Yes } & 27(24.5) \\ \text { Total } & 15(17.5)\end{array}$

Chi-Square

4.89796

\section{Preparation of Written Plans}

Partial/Complete
$1(3.6)$
$5(2.6)$
6
DF
1

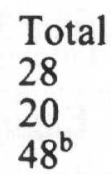

Significance .0383

Hypothesis $1 \mathrm{~b}$ : Formal export planning as a value and use of export planning advisors. ${ }^{\mathrm{a}}$

\section{Value Formal Planning}

$\begin{array}{ll}\text { No } & 22(18.1) \\ \text { Yes } & 9(12.9) \\ \text { Total } & 31 \\ \text { Chi-Square } & \\ 5.74855 & \end{array}$

\section{Use of Planning Advisors}

$\begin{array}{ll}\text { Moderate/Substantial } & \text { Total } \\ 6(9.9) & 28 \\ 11(7.1) & 20 \\ 17 & 48^{\mathrm{b}} \\ \text { DF } & \text { Significance } \\ 1 & .0182\end{array}$

a. Actual and (expected) frequencies are presented in the table cells.

b. Two firms did not answer the question on the value of formal planning. 
The findings for hypotheses 2, 3a, and $3 b$ are summarized in Exhibit 3. The Mann-Whitney $U$ test was utilized in each case. For hypothesis 2, results indicate higher export intensity exists for small firms whose leaders support (value) being formal with export planning than for those whose leaders do not.

The result for hypothesis $3 a$ suggests that higher export intensity does "not" exist for small firms that prepare written plans when compared to small firms that do not prepare written plans. Although the difference in export performance was in the hypothesized direction, it was not found to be statistically significant.

The final result concerns hypothesis $3 b$. The finding here was that there is support for the position that higher export intensity exists for small firms that use export advisors when compared to small firms that do not use these advisors.

\section{Discussion}

Most empirical studies to date on the planning and performance relationship have examined hypothesis $3 a$ (the relationship between business plan development and performance). Because the findings have been mixed, an evolving research interest has been to determine why this is so. Current study results are used to provide additional insights on this topic.

It can be suggested from this study that the preparation of a written export plan fits with the export planning value of being formal. This can be argued because a greater proportion of firms with leaders who valued being formal prepared written plans compared to those who did not value this activity $(5 / 20$ v. $1 / 28)$. Although this is a promising finding, export intensity performance did not

\section{Exhibit 3}

Relationships Between Strategic Export Planning Culture and First-Year Export Performance

Hypothesis 2: Formal export planning as a value and export intensity.

\begin{tabular}{ccl} 
Value Formal Planning & Mean Ranking of Export Intensity & $n$ \\
\hline No & 20.36 & 28 \\
Yes & 30.30 & 20 \\
U & $Z$ & $48^{\mathrm{a}}$ \\
164.0 & -2.4374 & Significance \\
& & .0074
\end{tabular}

Hypothesis 3a: Preparation of written export plans and export intensity.

\begin{tabular}{ccl} 
Export Plan Preparation & Mean Ranking of Export Intensity & $\mathrm{n}$ \\
\hline None & 25.11 & 44 \\
Partial/Complete & 28.33 & 6 \\
U & $\mathrm{Z}$ & 50 \\
115.0 & -.5097 & Significance \\
& & .3051
\end{tabular}

Hypothesis 3b: Use of export planning advisors and export intensity.

\begin{tabular}{ccl} 
Export Advisor Use & Mean Ranking of Export Intensity & $\mathrm{n}$ \\
\hline None & 22.09 & 32 \\
Moderate/Substantial & 31.56 & 18 \\
U & $\mathrm{Z}$ & 50 \\
179.0 & -2.2127 & Significance \\
& & .0134
\end{tabular}

a. Two firms did not answer the question on the value of formal planning. 
improve for firms that prepared written plans when compared with those that did not. It may be that the relationship between written plans and performance is blurred by other internal (organizational culture) factors as well as external (environmental) factors. Building on the organizational culture perspective developed in this study, further research could examine planning beliefs and norms. One planning belief that could be studied is: Do organizational leaders believe that superior performance results from formal rather than informal planning? Answering this question could be important because leaders of small firms may prepare written export plans based on the requirements of an external capital provider, not based on their own belief that superior export performance will result from the documentation. Another fertile direction for research includes testing the influence of wider environmental factors and industry dynamics on the relationship between formal planning and performance.

A second discussion area involves making comparisons between the planning practices of developing a written plan and using export advisors. This is possible with the current study since one of its unique features is that information on both practices is available. One observation is that only six firms prepared a written (partial or complete) export plan while three times that number used advisors (18) to either support or actively shape export decisions.

The two practices can also be contrasted using the results of the cultural value question and the export intensity question. A comparison of the value question and each of the practices did not generate any distinctions. That is, for both of the two practices there was a significant relationship with the value of being formal. This did not occur for the export intensity question. Although the difference in export intensity for those who did and those who did not prepare a written plan was not significant, the difference was significant for those who did and those who did not use advisors (i.e., mean export intensity was higher, as hypothesized, for those using advisors).

These comparisons suggest that more export research emphasis be given to the use of advisors. Future studies on the use of advisors could focus on gathering additional information about these people and their roles. Survey questions might ask: number of advisors used, types of advisors used (e.g., internal board members versus external consultants, and domestic versus foreign consultants), the extent or degree to which advisors were used, and the topics on which advisors provided information or consultation.

The major study findings also offer practical guidance to entrepreneurs who are debating exporting. It is well known that texts in this area prescribe planning as fundamental to success. The results of this research offer two specific advancements to the planning prescription. First, small businesses in the study whose leaders valued formal export planning were found to outperform those firms whose leaders did not. Entrepreneurs, therefore, should consider the support they give to formal planning as critical. Second, statistical significance in the study was found for the use of advisors and not for preparing written plans. Consequently, entrepreneurs should be encouraged to use advisors in the export planning process.

Limitations of the current study include sample and measurement issues. One sample concern is the 17 percent response rate. This figure could be viewed as low in some research fields, but it falls within the range of response rates (3\% to $80 \%$ ) reported for small business studies (Alpar and Spitzer, 1989). In terms of measurement issues, ideally, it would be best to obtain information about a firm's first year of exporting on a real-time basisduring the time it is occurring. It is difficult, however, to obtain a large list of small firms that are currently in their first export year. Further, although the use of retrospective measures is often perceived as introducing biases into research results, when the event being studied is a significant one, such as export initiation, retrospective recall is considered to be more accurate than otherwise might be expected (Auriat, 1993). In conclusion, the authors do not believe that these limitations seriously cloud the important relationships found in this study between export planning values, practices and performance.

\section{References}

Aaby, N.E., and S. F. Slater. 1989. "Management influences on export performance: A review of the empirical literature 1978-88." International Marketing Review, 6:4, 7-26.

Alpar, P., and D. M. Spitzer, Jr. 1989. "Response behaviour of entrepreneurs in a mail survey." Entrepreneurship Theory and Practice, 14:2, 31-45.

Armstrong, J. S. 1982. "The value of formal planning for strategic decisions." Strategic Management Journal, 3: 197-211.

Auriat, N. 1993. 'My wife knows best' a comparison of event dating accuracy between the wife, the husband, the couple, and the Belgium population register." Public Opinion Quarterly, 57: 165-190. 
Bijmolt, T. H. A., and P. S. Zwart. 1994. "The impact of internal factors on the export success of Dutch small and medium-sized firms." Journal of Small Business Management, 32:2 (April), 69-83.

Bilkey, W.J. 1978. "An attempted integration of the literature on the export behavior of firms." Journal of International Business Studies, 9:1 (Spring-Summer), 33-46.

Brasch, J. J., and W. Lee. 1978. "The adoption of export as an innovative strategy." Journal of International Business Studies, 9:1 (Spring-Summer), 85-93.

Bracker, J.S., B. W. Keats, and J. N. Pearson, J.N. 1988. "Planning and financial performance among small firms in a growth industry." Strategic Management Journal, 9: 591-603.

Bresser, R.K. and R. C. Bishop. 1983. "Dysfunctional effects of formal planning: Two theoretical explanations." Academy of Management Review, 8: 588-599.

Caruana, A., M. H. Morris, and A. J. Vella. 1998. "The effects of centralization and formalization on entrepreneurship in export firms." Journal of Small Business Management, 36:1 (January), 16-29.

Deal, T.E., and A. A. Kennedy. 1982. Corporate cultures: The rites and rituals of corporate life. Reading MA: Addison-Wesley.

Denison, D. R. 1990. Corporate culture and organizational effectiveness. New York: John Wiley and Sons.

Dillman, D. A. 1978. Mail and telephone surveys: The total design method. New York: Wiley.

Fredrickson, J. W. 1984. "The comprehensiveness of strategic decision processes: Extension, observations, future directions." Academy of Management Journal, 27:3, 445-466.

Gilmore, F. F. 1971. "Formulating strategy in smaller companies." Harvard Business Review, 49:71-81.

Hand, H. W., P. Sineath, and W. E. Howle. 1987. "Small business concepts and their relationship to performance: A field study of retail service stations." Journal of Small Business Management, 25:2 (April), 55-63.

Idaho Department of Commerce. 1994. Idaho international trade directory 1994-1995. Boise, ID: Idaho Department of Commerce.

Kamath, S., P. J. Rosson, D. Patton, and M. Brooks. 1987. "Research on success in exporting." In P.J. Rosson and S.D. Reid (Eds.), Managing Export Entry and Expansion. New York: Praeger, 398-421.

Lee, D., and J. Jang. 1998. "The role of relational exchange between exporters and importers: Evidence from smalland medium-sized Australian exporters." Journal of Small Business Management, 36:4 (October), 12-22.

Lyles, M. A., J. S. Baird, J. B. Orris, and D. F. Kuratko. 1993. "Formalized planning in small business: Increasing strategic choices." Journal of Small Business Management, 31:2 (April), 38-50.

Miesenbock, K.J. 1988. "Small businesses and exporting: A literature review." International Small Business Journal, 6:2 (January-March), 42-61.

Ouchi, W. 1981. Theory Z: How American business can meet the Japanese challenge. Reading, MA: AddisonWesley.

Parks, B., P. D. Olson, and D. W. Bokor. 1991. "Don't mistake business plans for planning (it may be dangerous to your financial health)." Journal of Small Business Strategy, 2:1, 15-24. 
Pearce, J. A., E. B. Freeman, and R. B. Robinson. 1987. "The tenuous link between formal strategic planning and financial performance." Academy of Management Review, 12:4, 658-675.

Peters, T. J. and R. H. Waterman. 1982. In search of excellence: Lessons from America's best run companies. New York: Harper and Row.

Robinson, R.R. 1982. "The importance of 'outsiders' in small firm strategic planning." Academy of Management Journal, 25:1 (March), 80-93.

Robinson, R. B., and J. D. Pearce. 1983. "The impact of formalized strategic planning on financial performance in small organizations." Strategic Management Journal, 4: 197-207.

Rue, L. W., and N. A. Ibrahim. 1998 "The relationship between planning sophistication and performance in small business." Journal of Small Business Management, 36:4 (October), 24-32.

Schein, E. G. 1985. Organizational culture and leadership. San Francisco: Jossey-Bass.

Shrader, C. B., L. Taylor, and D. R. Dalton. 1984. "Strategic planning and organizational performance: A critical appraisal." Journal of Management, 10:2, 149-171.

Shuman, J. C., J. J. Shaw, and G. Sussman. 1985. "Strategic planning in smaller rapid growth companies." Long Range Planning, 18:6, 48-53.

Still, T. W. 1974. An exploratory investigation of strategic planning behavior in small businesses. Unpublished doctoral dissertation, Florida State University.

Trice, H. M. and J. M. Beyer. 1993. The cultures of work organizations. Englewood Cliffs, NJ: Prentice-Hall.

Zahra, S. A., D. O. Neubaum, and M. Huse. 1997. "The effect of the environment on export performance among telecommunications new ventures." Entrepreneurship Theory and Practice, 22:1 (Fall), 25-46.

\section{MEjE}

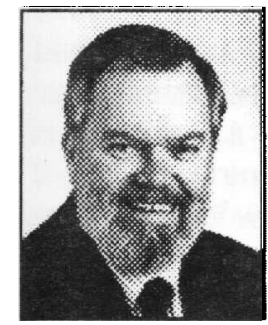

Philip D. Olson (polson@uidaho.edu), Ph.D., is a professor of business at the University of Idaho. His teaching and research interests incude entrepreneurship, strategy, and organization theory. His research has appeared in Journal of Small Businss Management, Entrepreneurship: Theory and Practice, Business Horizons, Journal of Business Strategy, and California Management Review.

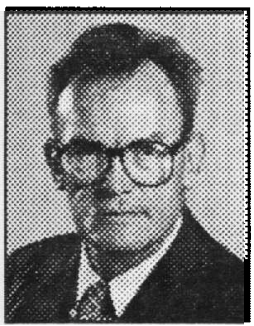

Newell Geogh (rmggough@cobfac.idbus.edu) is associate professor and chairman of the Department of Management at Boise State University. He received his Ph.D. from the University of Utah. Dr.Gough regularly teaches courses in strategic management at the graduate and undergraduate levels. He also developed the new venture course for undergraduates and the advanced entrepreneurship elective for MBA and engineering students.

His research interests include corporate entrepreneurship, corporate governance, the planningperformance relationship in small firms, and mergers and acquisitions by large and small firms. Dr. Gough has presented papers at Babson Research Conferences, Strategic Management Conferences, ICSM Conferencs, and USASBE Conferences. His most recent publications have appeared in Frontiers of Entrepreneurship Research, Journal of Enterprising Culture, and Journal of Small Business Strategy. 